\title{
O HIV, O CIBORGUE, O TECNOBIODISCURSIVO
}

\section{THE HIV, THE CYBORG, THE BIO-TECHNOLOGICAL- DISCOURSIVE}

\section{Atilio Butturi Junior*}

Todo mundo tem mais ou menos a peste, somos todos pestíferos, mas é necessário muito esforço para não transmiti-la; nós nos cansamos, então chega a peste.

Albert Camus, A Peste

\section{RESUMO}

O presente artigo pretende fazer uma leitura do dispositivo crônico da aids a partir das discussões sobre o pós-humanismo, tendo como pressuposto o conceito de tecnobiodiscursivo e seus efeitos. A hipótese a ser defendida é que esse dispositivo funcionaria como um modelo provocativo do pos-humanismo. Para tanto, inicialmente recorre à caracterização do tecnobiodiscursivo, segundo a ordem da cisão entre as modalidades de vida que, no capitalismo tardio, tem inscrições híbridas e colocam em suspenso categorias isoladas de corpo, sujeito e discurso. Depois, parte-se para uma descrição do dispositivo crônico da aids, a partir de uma breve genealogia, de modo a relacionar a cronicidade e suas estratégias médico-farmacológicas a novas modalidades de vida. Por fim, atenta-se para a possibilidade de aduzir, das discussões entre dispositivo e acontecimento tecnobiodiscursivo, um modelo provocativo de pós-humano.

Palavras-chave: hiv-aids; pós-humano; tecnobiodiscursivo.

\section{ABSTRACT}

This article seeks to approach the chronic apparatus of AIDS via discussions on posthumanism, assuming the concept of bio-technological-discoursive and its effects. The thesis being defended is that this apparatus would function as an explanatoryprovocative paradigm of posthumanism. Therefore, it initially analyzes the characterization of discussions on bio-technological-discoursive, based on the order of the division between the modalities of life that, in late capitalism, have hybrid inscriptions and hold isolated categories of body, subject, and discourse in abeyance. It then offers a description of the chronic apparatus of AIDS, starting with a brief genealogy, in order to connect chronicity and its medical-pharmacological strategies to new modalities of life. Finally, it considers the possibility of introducing, from discussions between apparatus and discussions on bio-technolocal-discoursive event, a posthuman provocative model. Keywords: hiv-aids; posthuman; bio-technological-discoursive.

\footnotetext{
* Universidade Federal de Santa Catarina (UFSC), Programa de Pós-Graduação em Linguística, Florianópolis, SC, Brasil. atilio.butturi@ufsc.br, https://orcid.org/0000-0002-9985-2259
} 


\section{INTRODUÇÃO}

Inicio meu texto com três recortes. O primeiro, de Bruno Latour (1994, p.8, grifos meus). O francês abre o seu Jamais fomos modernos a partir de um enunciado sobre o hiv':

[...] o menor vírus da AIDS nos faz passar do sexo ao inconsciente, à Africa, às culturas de células, ao DNA, a São Francisco, mas os analistas, os pensadores, os jornalistas e todos os que tomam decisões irão cortar a fina rede desenhada pelo vírus em pequenos compartimentos específicos, onde encontramos apenas ciência, apenas economia, apenas representações sociais, apenas generalidades, apenas piedade, apenas sexo.

A crítica da modernidade de Latour, como se sabe, volta-se para dois pontos: de um lado, a tradução e os esforços de purificação, na mesma medida em que os híbridos proliferam; do outro e a reboque, a cisão entre a natureza, a política e o discurso. O hiv nesse caso - assim como outros dos exemplos de Latour apareceria justamente no hífen que contesta o moderno e demanda outros modelos explicativos para o mundo.

O segundo dos enunciados é de Donna Haraway (2000, p.59). No Manifesto Ciborgue, ela vai pensar seus híbridos também a partir do hiv. Ora, se a autora afirma que a biopolítica é um "conceito débil" e apenas uma "premonição da políticaciborgue", em seu quadro da nova "informática da dominação" ela inscreve uma mudança: "Microbiologia, tuberculose > Imunologia, AIDS". Na aids, a contestação de Haraway sobre os limites do humano ficam mais visíveis: trata-se de um objeto nem natural nem tecnológico, mas - novamente - de um híbrido de natureza e política.

O terceiro recorte é de Didier Fassin (2006), tirado do seu Quand les corps se souviennent: expériences et politiques du sida en Afrique du Sud. No livro, que descreve uma espécie de genealogia da aids na África do Sul, Fassin coloca em discussão a relação entre a natureza da doença, a produção dos corpos doentes e as relações políticas que produzem objetos ambíguos, rasurados. Ora, o autor aponta que é justamente por negar a humanidade a certos sujeitos que a aids se apresenta como uma espécie de modelo da necropolítica, conforme pensada por Mbembe (2016). A necropolítica como extermínio se justificaria, porém, apenas se lida em sua complexidade: negar a humanidade daqueles que vivem com hiv é um efeito de relações internacionais, econômicas, de representação e do apartheid. Para Fassin (2006), cultura patriarcal

1. No texto, grafo hiv e aids em minúsculas. O gesto é o da memória dos primeiros militantes brasileiros, que pretendiam indicar a força da resistência no modo de inscrever as palavras. 
e terrorismo envolvem a epidemia africana - e é no interior dessa densidade que a epidemia deve ser tomada ${ }^{2}$.

Como se pode notar, os três recortes tematizam o hiv. Mas não apenas isso. O que eles solicitam é um novo pacto ontológico, uma nova forma de inteligir o vírus, a síndrome, o soropositivo. Nos três casos, o que está em jogo é, ainda, algo que nos remete à cisão entre as formas de vida e à matabilidade. Aqui, parto do que Foucault (2010a), na última aula do seu Racialização Em Defesa da Sociedade, revela: nas sociedades biopolíticas modernas e contemporâneas, o imperativo de "fazer viver" inaugurou também a possibilidade de cindir as modalidades de vida. Há, portanto, a partir de uma matriz biológica, a separação entre os puros e os impuros, os mais ou menos humanos. O nazismo teria sido o epítome desse processo racializador que, entretanto, permanece em funcionamento, de formas mais ou menos sutis, no que Foucault (2010a) chama de "racismos indiretos" - a morte civil, a exclusão.

Além de um problema sobre a vida, a biopolítica atual também se produziria num problema sobre o luto. Assim, partindo da mesma separação - desigual - dos discursos sobre a humanidade, Judith Butler (2016) em Quadros de Guerra e O Clamor de Antígona vai se valer dos discursos e das práticas sobre o hiv para pensar o que chama de "distribuição desigual do luto público" e a possibilidade de criar modos de resistência. Se Antígona era aquela que colocava em jogo a própria separação generificada das vidas que valem mais ou menos, o acontecimento do hiv e da aids teria materializado um novo racismo, ao mesmo tempo incidindo sobre a vida dos soropositivos e sobre a impossibilidade de prantear sua morte, porque escandalosa:

Nos primeiros anos da epidemia da aids nos Estados Unidos, as vigílias públicas e o Name Project conseguiram superar a vergonha pública associada à morte por complicações decorrentes da aids, uma vergonha associada algumas vezes à homossexualidade, especialmente ao sexo anal, e outras vezes às drogas e à promiscuidade. (BUTLER, 2016, p. 65, grifos meus)

Entre os três recortes e as ponderações sobre o racismo e o luto, gostaria de apontar alguns vértices. Primeiro, a ligação entre o hiv e a biopolítica-necropolítica. Depois, a centralidade, no dispositivo da aids (ver adiante), de estratégias de suspeição em relação a certas modalidades de vida. Por fim - e não menos importante -, as práticas e estratégias de manutenção da vida crônica que serão inventadas para o enfrentamento da epidemia.

2. Fassin (2006) narra o período em que o então presidente da África do Sul, Thabo Mbeki (19992008, eleito após Mandela), negou a existência do hiv (no Washington Post em 19 de abril de 2000 e em conferências internacionais) e criou uma controvérsia acerca da aculturação da biomedicina (o salto estatístico de menos de um por cento nos anos noventa para percentuais de 25 a 36 por cento). $\mathrm{Na}$ sua Letter to World Leaders, ele questiona a aids a partir do etnocentrismo de que se diz vítima, perguntando se não havia imposição da experiência ocidental. 
É a partir desses vértices que construo este artigo, cujo objetivo é sugerir um modelo provocativo para pensar a biopolítica segundo a ordem do pós-humano, a partir da cronicidade da pessoa que vive com hiv sob a tutela da Terapia Antiretroviral (TARV), levando em conta: a) o caráter híbrido e ciborgue que sustenta a vida com hiv a partir da ascese biomédica da TARV; b) o caráter tecnobiodiscursivo da aids, doença e discurso produzidos no limite entre a vida, a linguagem e a política (PATTON, 1990; TREICHLER, 1987). Por sua vez, o uso da provocação-ao invés de categorias como paradigma ou hipótese -, aqui, encerra o desejo de não totalizar os acontecimentos tecnodiscursivos, mas pensá-los naquilo que, tensionados, podem oferecer como modalidades de invenção de si e de deslocamentos nos dispositivos e nos diagramas nos quais nos produzimos.

Para tanto, divido o texto em três momentos. Inicialmente, descrevo o tecnobiodiscursivo e suas implicações para pensar o sujeito e as categorias de humanidade; depois, volto-me ao dispositivo crônico da aids e suas ambiguidades tecnobiodiscursivas; outro, em que aproximo dispositivo crônico e teoria ciborgue; por fim, na última seção sugiro que o dispositivo crônico da aids pode ser lido na forma de um paradigma tecnobiodiscursivo.

\section{O TECNOBIODISCURSIVO}

O pensamento aristotélico sobre a vida e suas diferentes formas se tornou célebre com Hannah Arendt (2007). Em A Condição Humana, ela mostra que Aristóteles tomou os dois modos pelos quais os gregos se referiam à vida: a bíos, específica dos humanos, da ordem do logos e capaz de estabelecer uma narrativa organizada; a zoé, vida de todos os seres (humanos e não humanos), da ordem do grito e da natureza compartilhada por todos os seres, a vida meramente natural.

Giorgio Agamben (2014, p.11) afirma que Arendt reivindica para a modernidade um "[...] processo que leva o bomo laborans e, com este, a vida biológica como tal, a ocupar progressivamente o centro da cena pública do moderno." A decadência do espaço público da modernidade (e da política) seria um produto daquilo que também Michel Foucault (2009) colocaria em discussão para fundamentar o debate sobre a biopolítica, em A Vontade de Saber: a vida natural passa a ser reivindicada como objeto de problematização e de cálculo do Estado governamentalizado e "a política se transforma em biopolítica" (2014, p.11). Foucault (2009, p.133) é retomado por Agamben justamente na sua implicação aristotélica da divisão entre a zoé e bíos, então invertida: 
[...] o que se poderia chamar de "limiar de modernidade biológica" de uma sociedade se situa no momento em que a espécie entra como algo em jogo em suas próprias estratégias políticas. O homem, durante milênios, permaneceu o que era para Aristóteles: um animal vivo e, além disso, capaz de existência política; o homem moderno é um animal, em cuja política, sua vida de ser vivo está em questão.

A aparição da vida do homem como temática dos estudos foucaultianos é pouco anterior e diz respeito justamente à relação entre duas ordens: a do corpo disciplinado e a das regulações do governo. É essa entrada do poder como um problema macroeconômico fundante que vai aparecer já alguns anos antes da publicação de Vontade de Saber, nas conferências que realizou em 1974 no Brasil (no então Instituto de Medicina Social da Universidade do Estado da Guanabara), quando Foucault (2010b) usará pela primeira vez o termo biopolítica, para dar conta dos deslocamentos que o capitalismo operou, desde o século XVIII, em direção a uma medicina coletiva, uma estratégia em que o corpo como força de produção e positividade passou a ser investido. Foucault (2010b, p.169-170) tomará o Plano Beveridge (1940-1945) como objeto de discussão da primeira das conferências (de outubro de 1974) e afirmará que, desde então "a saúde entra no campo da macroeconomia" na constituição de uma nova forma de governo liberal, em que têm lugar a "[...] formulação de um novo direito, uma nova moral, uma nova economia, uma nova política do corpo".

Foucault (2009, p.159) apontou que, para que a biopolítica passasse a funcionar, a sexualidade como dispositivo teria sido uma condição: "O sexo é o acesso, ao mesmo tempo, à vida do corpo e à vida da espécie". Como dispositivo, a sexualidade é apresentada na forma de um conjunto híbrido de estratégias políticas que respondem a urgências históricas e materializada tanto em práticas quanto em discursos, tanto na arquitetura quando nas instituições, tanto no corpo quando na linguagem.

Tanto os dispositivos quanto o paradigma biopolítico como governo da vida receberão leituras contemporâneas que dizem respeito às transformações sociais, políticas e subjetivas em curso. Interessa-me, pois, apontar como um paradigma biopolítico pode ser lido segundo o recrudescimento da linguagem e das tecnologias, na modalidade de um tecnobiodiscurso. Ademais, é preciso considerar, então, os impactos que esse universo tecnobiodiscursivo oferece para a produção de discursos sobre o humano, cuja marca é a suspeição diante de categorias como natureza e pessoa humana, justamente pela intervenção constitutiva de técnicas biotecnológicas que implicam mudanças da própria definição de humanidade (LECOURT, 2005). Efeito das tecnologias e do que se tem lido como ocaso do 
iluminismo desde as discussões pós-modernas (RÜDIGER, 2007), a discussão do pós-humano implica pensar os limites da modernidade:

Ironicamente, são os processos que estão transformando, de forma radical, o corpo humano que nos obrigam a repensar a "alma" humana. Quando aquilo que é supostamente animado se vê profunda e radicalmente afetado, é hora de perguntar: qual é mesmo a natureza daquilo que anima o que é animado? É no confronto com clones, ciborgues e outros híbridos tecnonaturais que a "humanidade" de nossa subjetividade se vê colocada em questão. (TADEU, 2010, p.10)

Dessa perspectiva, o conceito de disciplina e de biopolítica foucaultiano começam a ser debatidos, tendo em vista outras urgências tecno-históricas. Se, para Deleuze (2013), a desterritorizalização e a multiplicação dos dispositivos corresponderia à multiplicidade de formas de subjetividade e de estratégias de governo mais difusas e potentes do que aquelas com que havia se preocupado Michel Foucault, parte da discussão sobre os dispositivos biopolíticos contemporâneos passará a atentar para essas novas formas de governo que surgem a partir da década de setenta do século XX. Segundo pressupostos distintos e a partir de Michel Foucault, Antonio Negri (2016) aponta, como característica da organização do capitalismo neoliberal, a subsunção do social pelo capital, ou, dito de outro modo, pelo fim da separação entre a infraestrutura e a superestrutura na tradição teórica. À Foucault, Negri vai fazer corresponder a aparição da biopolítica como um tema na mesma viragem do capitalismo. Essa nova forma de biopolítica, ampliada para os regimes tecnológicos e para formas híbridas de vida, dizem respeito a novas formas de soberania, a novos fluxos de capital e de trabalho.

Também pensando na contemporaneidade e nas sociedades do controle, Lazzarato (2006) vai se ocupar dos dispositivos, sobretudo naquilo que aproximam natureza e tecnologia, vida natural e artificial, discursivo e não-discursivo. É essa ausência de fulcro único que caracterizaria o governo biopolítico:

Os regimes de signos, as máquinas de expressão,os agenciamentos coletivos de enunciação (o direito, os saberes, as linguagens, a opinião pública) agem como engrenagens dessas maquinações, da mesma forma que os agenciamentos maquínicos (fábricas, prisões, escolas). (LAZZARATO, 2006, p.64)

Lazzarato aposta num adensamento da biopolítica, fundamentado justamente na desterritorialização deleuziana do controle. Como signo e como máquina, esse deslocamento exige novas redes e novas velocidades, que não a da modernidade. Assim como Peter Sloterdijk (1999), no seu Regras para o parque bumano (1999), tratase de pensar um "conflito de mídias" novo. Se, para Sloterdijk (1999), o humanismo se fundava na prevalência do livro sobre o anfiteatro (a luta, a cena pública), o que lemos hoje é a ambivalência do humano em sua abertura biológica e em sua 
apropriação alfabética linguageira. Nesse caso, Nietzsche é aquele "[...] que leu com a mesma atenção Darwin e S. Paulo [...]" (SLOTERDIJK, 1999, p. 39), que solicitou um modo de inteligir o mundo e o sujeito como natureza e como técnica de si.

Esse adensamento da biopolítica, que leva em consideração as novas modalidades de vida híbridas, racializadas e tecnológicas, é o ponto de partida de Paul B. Preciado (2008, p.295), no Testo Yonqui. Para o autor, tanto Sloterdijk quanto Haraway permitiriam evitar metafísicas fascistas sobre a biopolítica e a técnica - nem a tentação messiânica de uma tecnologia salvadora, nem a tentação apocalíptica de um controle total. Preciado toma do ciborgue de Haraway seu conceito de tecnobiopoder e o conceito de império de Hardt e Negri (2011) para forjar a discussão sobre o "capitalismo farmacopornográfico da sexopolítica": vértice entre o semiótico-técnico da representação pornográfica e tecno-orgânico da intervenção sobre os corpos - da pílula ao Viagra, passando pela Testosterona e pela invenção do conceito de gênero, uma tecnologia nos moldes do dispositivo foucaultiano, como gostaria De Lauretis (1994).

Ao retomar a distinção aristotélica sobre as modalidades de vida, Preciado (2008, p.43) vai inserir justamente o problema da tecnologia que invade a vida e dessa tecnovida materializada em corpo e em discurso como estratégia de exploração e de separação entre vidas mais ou menos humanas. Estamos na era da bioeletrônica da excitação global dos corpos e da proletarização pornográfica e espetacularizada dos trabalhadores: "[...] corpos pornográficos, cuja vida (condição técnica mais que puramente biológica), desprovida de direitos de cidadania, [...] está exposta e construída por aparatos de autovigilância, publicidade e mediatização globais".

Diante das implicações tecnobiodiscursivas, o que Preciado sugere é uma série de resistências de (tecno)gênero, apelando para a biopotência (numa leitura deleuziana de uma vida ou na relação entre molar e molecular retomada por Lazzarato e Virno): uma espécie de cuidado de si, de bioascese que é a criação de um híbrido na ambiguidade da Testosterona: usada na guerra, por soldados nazi, mas agora para uma reprogramação que resiste ao binarismo de gênero - uma experimentação biopolítica ciborgue que não redunda nem em lumpetização nem em controle. Como na ambiguidade da biopolítica foucaultiana diante da tanatopolítica racializadora, o que Preciado (2008) percorre é, ainda, a senda de Foucault (2018): há um processo de negação das identidades, em aberto, a partir do que se produzem as condutas de resistência. No caso de Preciado, é na intersecção biotecnodiscursiva que a transgressão se torna possível, segundo a ordem de um ciborgue e numa pirataria que interdita os binarismos e coloca em xeque as distinções que precarizam certas vidas. 
Aqui, o registro é similar àquele de que partia Haraway (2000, p.45) na construção de seu mito político: "[..] meu mito do ciborgue significa fronteiras transgredidas, potentes fusões e perigosas possibilidades - elementos que as pessoas progressistas podem explorar como um dos componentes de um necessário trabalho político.".

Ora, é nessa topologia política de racialização tecnobiodiscursiva que o acontecimento do hiv e da aids tem espaço e solicita, a um só tempo, um novo modo de entender a doença, o doente e as tecnologias, bem como as formas de subjetividade híbridas que a cronicidade oferecem. Ademais, trata-se de um dispositivo que diz respeito a formas de separar vidas mais ou menos promíscuas, mais ou menos culpadas, cuja distinção é realizada no interior de dispositivos sexuais e de gênero. Dito de outro modo, a soropositividade demanda uma ascese corporal subjetiva e as políticas de enfrentamento se sustentam em enunciados de controle biomédico e moral. Como aponta Preciado (2008, p.255), esses dispositivos - em sua constituição agonística -, abrem espaço também para outras formas de conduta e de produção de si no interior das tecnologias e dos discursos.

Frente ao paroquianismo e a doutrinação moral que tem dominado as políticas feministas, queer e a prevenção da aids, é necessário desenvolver micropolíticas de gênero, de sexo e de sexualidade, baseados em práticas de autoexperimentação (mais que de representação) intencionais que se definam por sua capacidade de rechaçar e de resistir à norma, de criar novos planos de ação e de subjetivação.

É, pois, esse dispositivo da aids e suas rasuras que interessam à próxima seção.

\section{UM DISPOSITIVO CIBORGUE}

Começo esta seção com outros dois recortes:

Tivicay não cura a infecção pelo HIV, ele reduz a quantidade de HIV no organismo, mantendo-a num nível baixo. Além disso, promove o aumento na contagem das células CD4, tipo de glóbulo branco do sangue que exerce papel importante na manutenção de um sistema imune (de defesa) saudável, ajudando a combater as infecções. (TIVICAY, 2019)

Os efeitos colaterais do Efavirenz incluem vermelhidão e coceira na pele, náuseas, tonturas, dor de cabeça, fadiga, tonturas, insônia, sonolência, sonhos anormais, dificuldades de concentração, visão turva, dor de estômago, depressão, comportamento agressivo, pensamentos suicidas, problemas de equilíbrio e convulsões.

Os efeitos colaterais do Tenofovir incluem vermelhidão e coceira na pele, dor de cabeça, diarreia, depressão, fraqueza, náuseas, vômitos, tontura, gases intestinais, problemas renais, acidose láctica, inflamação do pâncreas e fígado, dor de barriga, alto volume de urina, sede, dor e fraqueza muscular, e dor e enfraquecimento dos ossos. 
Os efeitos colaterais da Lamivudina incluem dor de cabeça e no estômago, cansaço, tontura, febre, náuseas, vômitos, diarreia, febre, pancreatite, vermelhidão e coceira na pele, sensação de formigamento nas pernas, dor nas articulações e nos músculos, anemia, queda de cabelo, acidose láctica e acúmulo de gordura [lipodistrofia leve].

Retomo o recorte inicial deste artigo. Quando descreve as modificações da "informática da dominação" constitutiva da aparição do ciborgue, Haraway (2000, p.59) indica que passamos da Microbiologia, tuberculose para a Imunologia, AIDS. Haraway aponta que se as categorias anteriores não poderiam ser tomadas como naturais, no capitalismo tardio tratava-se de agir sobre as fronteiras. Assim, depois da Segunda Guerra Mundial aconteceu uma remodelação de corpos e identidades obedecendo a um tipo novo de controle, baseado em tecnologias de comunicação e em biotecnologias. A biologia como codificação - "uma espécie de criptografia" (HARAWAY, 2000, p.65) - materializar-se-ia na inscrição corporal da aids em gays e usuários de drogas, "decodificada" no limite entre a poluição e ausência de fronteiras.

O texto de Haraway, como se sabe, foi publicado em 1985. Gostaria de observar o funcionamento discursivo ciborgue entre aquela invenção da aids (PATTON, 1996; CAMARGO JUNIOR, 1994) e o excerto que abre esta seção: a bula do Tivicay. Tivicay é o nome comercial do Dolutegravir, inibidor de integrase distribuído desde 2017, gratuitamente, como tratamento de entrada para soropositivos no Brasil ${ }^{3}$. Não é difícil ler ali os enunciados tecnobiopolíticos do ciborgue de Haraway: Tivicay é uma forma de inteligência, capaz de quebrar a criptografia do hiv e manter as células saudáveis; é da ordem do cálculo-contagem, como uma ferramenta neoliberal (FOUCAULT, 2008) de controle o otimização do que vive; insinua-se na fronteira entre a poluição "a combater" e o corpo "saudável". Como operação microbiológica, ainda, esse antirretrovital (ARV), eu diria, solicita ao sujeito uma relação direta, obsedante e ascética diante das tecnologias biomédicas de controle. Dito de outro modo, a condição de viver com hiv e de ser sujeito só se efetiva com a adesão à tecnologia de codificação de Tivicay - e de outros ARVs.

Passo ao segundo dos excertos, retirado da bula de outro medicamento, conhecido no Brasil como $3 \mathrm{~cm}$ 1. Combinado de três substâncias - Tenofovir (300 mg), Lamivudina (300 mg) e Efavirenz (600 mg) - o 3 em 1 passou a ser distribuído

3. O Dolutegravir passou a ser distribuído como tratamento de entrada para soropositivos no Brasil apenas em 2017. Em 2018, a nota informativa $N^{\circ}$ 03/2018 do Departamento de Vigilância, Prevenção e Controle das IST, dos HIV/Aids e das Hepatites Virais (2018), "Apresenta as recomendações de substituição (switch) de esquemas de terapia antirretroviral contendo ITRNN ou IP/r por Dolutegravir, para pessoas vivendo com HIV com supressão viral maiores de 12 anos de idade", que torna possível o acesso a todas as pessoas vivendo com HIV, maiores de 12 anos de idade com supressão viral. 
no Brasil em janeiro de 2015, como estratégia de adesão. Interessa aqui, porém, marcar a ambiguidade biopolítica de acordo com a série de efeitos colaterais possíveis para os medicamentos. O Efivarenz tem patente de 1998 e já em 2015 o Dolutegravir (em tese, menos agressivo) já estava em circulação. Tendo em vista a propaganda institucional de êxito no enfrentamento do hiv e da aids (BIEHL, 2004), interessa pensar justamente os limites do governo da vida dos soropositivos e os documentos de saúde pública, forjados atualmente no uso dos medicamentos como modelo de diminuição da contaminação.

Não quero reduzir o dispositivo da aids à ordem dos fármacos. Porém, na modalidade da tecnologia, como aponta Preciado (2008, p.51), o que suas bulas materializam é um "manual de micro-fascismo". Ou, de outra sorte, os medicamentos funcionam como um "panopticon comestível". Os fármacos, no limite, indicam os caminhos pelos quais, pelo corpo e no vértice com a tecnologia, os sujeitos soropositivos são controlados, esquadrinhados, assujeitados e racializados. Eles funcionam, ainda, segundo uma codificação tecnobiopolítica e um controle tecnocorporal e discursivo: as linhas de força que compõem o dispositivo da aids.

Aqui, segundo linhas de confluência com a TARV, entendida como fármacopanopticon, cabe descrever o que se entende por dispositivo da aids e por dispositivo crônico da aids. Butturi Junior (2016) tem, a partir da consideração de Perlonguer (1987), refletido sobre o acontecimento da aids e do hiv sob a lógica dos dispositivos na qual estão em jogo uma disciplinarização dos corpos e do desejo e a medicalização dos sujeitos e da população. Entre os dois dispositivos, aparecem os enunciados de cronicidade e inventa-se uma vida com hiv.

Voltemo-nos para a invenção desses dispositivos. No caso do dispositivo da aids, é mister fazer notar que a aids implica, já desde sua aparição, um vértice entre o corpo e a linguagem, a doença e os discursos. Em seu texto clássico, Treichler (1987, p.32) afirma que a epidemia da aids é "[...] simultaneously an epidemic of a transmissible lethal disease and an epidemic of meaning or signification". Essa luta discursiva materializava nos discursos sobre uma praga gay até a condenação do sexo, passando pelo fascismo contra os homossexuais até as narrativas de um plano soviético para acabar com o Ocidente capitalista (TREICHLER, 1987). No Brasil, Daniel e Parker (1991, p.13) afirmarão que são três as epidemias da aids: a primeira, quando seu aparecimento quase não foi despercebido ou discursivizado; a segunda, a produção da aids como doença infectocontagiosa; a terceira, a "[...] epidemia de reações sociais, culturais, econômicas e políticas à AIDS".

$\mathrm{O}$ que esses autores pretendem esclarecer é que a aids, na medida em que solicita corpos, instituições, discursos etc., mostra sua complexidade como 
fenômeno limite da tecnobiopolítica. Patton (1990), na mesma esteira, notará que o aparecimento da aids está relacionado à grande visibilidade gay dos anos setenta. É porque havia uma comunidade discernível, uma população que poderia oferecer perigo, que se pode ligar as mortes por pneumonia (via Pneumocistis carinii) e a demografia gay entre 1980 e 1981 . De modo similar, é no mesmo movimento que relações sociais, políticas e culturais vão instaurar como perigosos os chamados "grupos de risco", conhecidos como 5H: hemofílicos, homossexuais, haitianos, heroinômanos e hookers (prostitutas). Um grupo de risco criado como estratégia biopolítica já no início da epidemia, nos idos de 1982 (CAMARGO JR., 1994), ainda num momento em que a etiologia da doença não havia sido sequer descrita.

Essa invenção da aids no interior de um dispositivo racializador, no começo da década de oitenta, valeu-se também dos efeitos de objetividade dos discursos científicos que produziram os enunciados sobre o "câncer gay" e a GRID (GayRelated Imune Deficiency), além de diversas explicações sobre a origem exterior e novamente racializada - do hiv e da difusão da aids: ora na África e de acordo com um padrão higienista e racista do século XIX, ora na América Central e a partir da licenciosidade radical dos negros do Haiti em contato com os homossexuais brancos promíscuos. (CAMARGO JR., 1994; DANIEL; PARKER, 1991; POLLAK, 1990; PERLONGHER, 1987).

Chamo a atenção, na esteira do discurso geopolítico da origem, para a manutenção de estratégias tanatopolíticas no dispositivo da aids. Herbert Daniel (1989), dessa perspectiva, vai apontar as estratégias de morte civil que a aids fez surgir. Os corpos e os sujeitos "aidéticos" estavam sujeitos tanto a um regime de controle quanto a um regime de exclusão. Numa modalidade de racismo indireto, deviam se sujeitar à biomedicina e a seus recursos pouco eficazes e sofrer as consequências da precarização de seus direitos e da estigmatização, por perigosas, de suas formas de vida. Naquilo que Pelúcio e Miskolci (2009, p.139) chama de sidanização, o sujeito era implicado duplamente, como agente da saúde individual e como risco para a saúde pública.

Nesse processo, as estratégias de normalização e de disciplinarização incidiram sobre os corpos e as formas de vida anormalizadas, que exigiram a retomada de discursos de conjugalidade e de produção de uma homossexualidade menos "perigosa" (BUTTURI JUNIOR, 2012). Junto à conjugalidade, o discurso dos grupos de risco - e sua memória, persistente - fará coro com os enunciados acerca do "aidético", espécie de sujeito perigoso por excelência (ao mesmo tempo promíscuo e responsável), que proliferam na midiatização da aids - amplamente 
documentada (TREICHLER, 1987; SOARES, 2001; PATTON, 1990; DANIEL; PARKER, 1991, PERLONGHER, 1987).

Da perspectiva das políticas públicas, ainda, esse dispositivo biopolítico demanda uma forma de governo também específica. Carrara (1994) vai caracterizar o modelo da aids como aquele da intervenção social, próximo da sífilis. Tratava-se de controlar, no continuum médico-jurídico, o risco que os soropositivos impunham à pureza do corpo social, mantendo, para tanto, a anormalização racializante. Aos perigosos, a exclusão e o controle.

Segundo a ordem do biotecnodiscursivo, é um fármaco que parece dar indicações sobre a complexidade entre o discurso, a natureza e a política, nos moldes de Latour (1994). Como epidemia ciborgue (HARAWAY, 2000), a aids tomará o AZT como uma espécie de palavra-valise, na qual as tecnologias e os discursos de exceção tanatopolítico podem conviver. Herbert Daniel (1990), nos anos noventa, vai mostrar os modos pelos quais a Zamivudina (AZT), reconhecida amplamente pela população como o "remédio para AIDS" nos anos oitenta e noventa, tem efeitos políticos, corporais e subjetivos potentes. $\mathrm{O}$ que o autor questiona, em seu O primeiro AZT a gente nunca esquece, é o funcionamento de um discurso biomédico híbrido, no qual está implicada uma memória discursiva de responsabilização e de morte:

É, pelo contrário, uma imposição autoritária, que submete o doente à imagem de sua mortalidade ("aguente todos os efeitos colaterais, é sempre melhor sofrer, do que morrer..."). Para medir este efeito, basta perguntarmos à maioria das pessoas o nome de um medicamento específico para a tuberculose, ou o nome de uma droga em uso para uma disfunção do aparelho digestivo. Quase ninguém sabe. No entanto, todo mundo sabe que o AZT é um remédio para AIDS [...] (DANIEL, 1990, paginação irregular)

A "imposição autoritária" a que se refere Herbert Daniel recobre os enunciados tecnobiodiscursivos desse dispositivo da aids. Daniel vai se referir aos processos dolorosos de adesão ao medicamento, à saúde debilitada como efeito colateral do qual não apenas é interdito fugir, mas, ainda, a partir do qual é preciso se subjetivar na modalidade da exceção e da culpa. Ao soropositivo, nesse dispositivo da aids, só é dada a garantia de sujeito desde que medicalizado e engajado numa ascese ambígua. O AZT não apenas é essa ascese do corpo: torna-se um modo de categorização racial. É um remédio que não cura, que prolonga a vida dos sujeitos que, "todo mundo sabe", são os "aidéticos". Uma abertura para a cronicidade.

Conforme afirmava Patton (1993), uma vez testado positivo para hiv, uma nova forma de sujeito é produzida, permanentemente estampada no DNA - esse código ciborgue (HARAWAY, 2000). Não obstante a fragilidade epistemológica 
desse dispositivo da aids, o que ele deixa materializada é uma urgência biopolítica: separar certos sujeitos que então ganham visibilidade, indexá-los no perigo. Depois, fazer a manutenção de sua vida de forma precária, a partir de práticas biomédicas e de exceção tecnobiodiscursiva ${ }^{4}$.

Ora, conforme Butturi Junior (2016), Butturi Junior e Lara (2018a, 2018b), o dispositivo da aids teria se deslocado em meados dos anos noventa, sob a égide da cronicidade trazida com a TARV ${ }^{5}$. A genealogia do hiv e da aids estaria marcada, de forma definitiva, por uma cisão - novamente, tecnobiodiscursiva: o surgimento do chamado coquetel e os discursos de cronicidade. Nos dois casos, estarão implicados uma forma de controle biotecnológico e um funcionamento discursivo.

Vejamos. Moulin (2010, p. 37), ao descrever a "invenção" das doenças crônicas, indica não apenas o problema crescente de definição da normalidade, mas a criação de uma vida cada vez mais sujeita ao governo biopolítico. Ademais, os discursos de adesão à TARV retomam a responsabilização e a culpabilização moral descritas por Daniel (1990) e incorporam nele os enunciados de direito e de cidadania. Nesse caso, a distribuição da TARV e o acesso a ela passam a ser uma garantia jurídica e também uma injunção ao tratamento que separa os "doentes" dos "pacientes crônicos" - as pessoas que vivem com hiv. A garantia jurídica, ambiguamente, não açambarca nem os riscos à vida do sujeito em tratamento (os efeitos colaterais) nem as formas deterioridadas de subjetivação que passam a ser enfrentadas pelo sujeito soropositivo que adere à TARV (SQUIRE, 2013; SOUTO, 2008; BUTTURI JUNIOR, 2016).

Observo mais detidamente essa nova forma de subjetividade crônica e a agonística tecnobiodiscursiva de sua constituição ciborgue. Como na primeira aparição da epidemia, o sujeito é tomado como culpado porque se submeteu ao risco perverso (SONTAG, 1989); diferentemente, porque tem acesso aos medicamentos, suas dificuldades de adesão são lidas como ausência de cuidado de si e, no limite, como risco de saúde pública - naquilo que se caracterizou como sidanização.

4. A soropositividade crônica, nesse novo dispositivo, vai transbordar os limites dos $5 \mathrm{H}$ e democratizar-se. No Ocidente, a incidência do hiv passa a atingir populações heterossexuais e cada vez mais vulneráveis socioeconômicamente, enquanto nos países da África explode o número de soropositivos sem acesso ao tratamento.

5. No Brasil, a Lei n. ${ }^{\circ}$ 9.313, de 13 de novembro de 1996, dispõe que "Os portadores do HIV (vírus da imunodeficiência humana) e doentes de AIDS (Síndrome da Imunodeficiência Adquirida) receberão, gratuitamente, do Sistema Único de Saúde, toda a medicação necessária a seu tratamento" (BRASIL, 1996). A partir de 1996, o Sistema Único de Saúde disponibilizará tratamentos para toda a população, de forma gratuita - reconhecidos como "coquetéis". Ao mesmo tempo, assiste-se à proliferação do ativismo (na forma, sobretudo, de ONGs). 
Dito de outro modo, a "nova normalidade" do dispositivo crônico da aids (VALDERRAMA, 2012) permanece colocando em jogo a tanatopolítica e a morte indireta de certos sujeitos. A relação entre a cronicidade, a adesão ao tratamento e a produção de sujeitos perigosos intensifica-se nesse deslocamento do dispositivo. Os enunciados científicos sobre o sujeito indetectável, que ganham fôlego desde Verzazza et al. (2008), cujos estudos (amplamente replicados e asseverados) concluíram que pacientes em tratamento com adesão à TARV são capazes de diminuir a presença do vírus no sangue a níveis indetectáveis. Isso significa não apenas a contenção do vírus no corpo, mas a criação de uma estratégia de controle da epidemia via medicalização, porque os indetectáveis não são capazes de transmitir o hiv. É dessa perspectiva que partem as inciativas de enfrentamento do hiv no mundo, calcadas no documento 90-90-90 An ambitious treatment target to belp end the AIDS epidemic, da UNAIDS (2014), e baseados na prática de Testar e Tratar. No Brasil, por exemplo, o enunciado indetectável = intransmissível é mote de campanhas e, inclusive, de um site, o Sou + Estou Indetectável (BRASIL, 2018) ${ }^{6}$.

Agonisticamente, a manutenção da normalidade permanece uma questão em aberto, sobretudo porque a adesão à TARV materializa uma cidadania biológica: "The medicalised HIV citizenship produced as a result is an emblematic example of the biological citizenship described by Foucault" (SQUIRE, 2013, p. 198). Nesse caso, é um corpo biológico (zoé) tomado como espaço de cidadania (bios) o objeto sobre o qual essa modalidade de governo incide: por um lado, garantindo a vida, na ordem de uma intervenção sintética e duradoura; por outro, estabelecendo a adesão como condição de normalidade exclusiva. Nesse tensionamento, a tecnosemiótica da TARV, materializada no conceito de coquetel, parece reapropriar-se dos enunciados do AZT: um conjunto de remédios que extrapola a farmacologia e implanta-se no imaginário como uma memória problemática. Não obstante as transformações pelas quais a TARV passou, é o enunciado de um coquetel, espécie de conjunto infindável e mortal de medicamentos, a marca que acompanha os soropositivos, que se oferece como enunciado, ao mesmo tempo técnico e político, de uma cisão entre a vida anterior e a vida com hiv, entre a normalidade e o excesso. É esse hífen entre o político, o tecnológico e o subjetivo que permanece como problema e que se coloca como possibilidade de leitura paradigmática do que venho, aqui, chamando de tecnobiodiscursivo.

A tarefa da última seção é descrever o esforço de paradigma.

6. A indetecção via tratamento, no Brasil, foi responsável, ainda, pela incorporação da PrEP (Terapia Pré-Exeposição) no SUS, em 2018. 


\section{UM MODELO DE PÓS-HUMANO?}

Roberto Esposito (2004), em Bíos, vai pensar nas ambiguidades da biopolítica, lida ao mesmo tempo na qualidade do que faz viver e do equaciona uma política de morte. Esposito, então, propõe seu paradigma imunitário para pensar a biopolítica: se há um limite tanatopolítico constitutivo de toda a política, a imunização funciona de modo semelhante, já que propõe, como manutenção da vida, um risco para a vida que é preciso combater e calcular.

Até esse momento, assim como sugeriu Esposito, este texto tem pretendido descrever o tecnobiodiscursivo e incluir o dispositivo crônico da aids como uma espécie de modelo dessa modalidade de governo da vida. Ora, também como Esposito, gostaria de sugerir aquilo que, no dispositivo crônico da aids, pode ser lido como um esboço de modelo para pensar o pós-humano. Na ordem do modelo, ainda em construção, pontuo três provocações, a saber:

A primeira diz respeito, logicamente, à exceção: o dispositivo crônico da aids, ao produzir cisões de várias ordens, na modalidade dos racismos indiretos, acaba por desumanizar certas vidas. Assim, acaba por colocar em xeque também o próprio conceito de vida e de vivo com que as sociedades operam e pelos quais somos governados.

A segunda diz respeito aos modos pelos quais a vida é mantida. Se Foucault (2010) apontava que a biopolítica levava às últimas consequências a manutenção da vida, o acontecimento da cronicidade e da vida soropositiva se dá apenas na condição da ascese biomédica e da adesão farmacológica. Isso tem, como efeito, a produção de discursos sobre as tecnologias, os corpos e os sujeitos que extrapolam os limites da natureza ou das ontologias naturalistas. Ser humano ou ser sujeito, num dispositivo crônico, é viver segundo a ordem da hifenização e do controle contínuo.

A terceira diz respeito ao caráter de phármakon do dispositivo. Jacques Derrida (2005 [1972], p.45), em A Farmácia de Platão, traz à tona o problema grego da linguagem como phármakon, aquilo que cura mas que também pode matar: "[...] a ideia de um bom uso da ciência ou da arte do médico, ainda se teria todas as chances de se enganar pela língua". Ora, no caso do dispositivo crônico da aids, estamos às voltas com uma série de ambiguidades "pharmacológicas": um discurso médico ambíguo de adesão que minora os efeitos subjetivos e corporais negativos para os soropositivos que usam a TARV; a série de políticas internacionais que invizibilizam certas comunidades de sujeitos ou estigmatizam outras, sob a égide dos enunciados de segurança - como os usuários de drogas, como as populações do continente africano, como os homossexuais masculinos e os $\mathrm{HSH}$ e suas práticas sexuais promíscuas e, no limite, os sujeitos que se recusam a aderir à $T A R V_{\text {; a amiguidade }}$ 
entre um código biológico e os códigos discursivos pelos quais os sujeitos são produzidos. Novamente, solicitando uma categorização de humanidade mais fluida e sempre-já constituída por discurso, técnica e política.

$\mathrm{Na}$ modalidade de um modelo provocativo do pós-bumano, então, o dispositivo crônico da aids coloca em suspenso, inclusive, os limites da resistência: qual o limite da criação das técnicas de produção de subjetividade quando para o ciborgue a relação com a tecnologia é uma condição de permanecer vivo?

$\mathrm{Na}$ tentativa de responder a essa pergunta e concluir minhas provocações, com Agamben (2000), gostaria de encerrar o texto. No momento das subjetividades proliferantes e do ocaso da política, é nos soropositivos que ele vislumbra uma abertura. É em suas lutas cotidianas e corporais por medicamentos menos tóxicos, em detrimento das lutas em nome de um sujeito universal e de um humano metafísico, que esses sujeitos informam sobre outra forma, digamos, pós-humana, de ser sujeito. No instante em que sua militância exige o limite da morte como experiência fundamental. No instante em que, em seu discurso e em seu corpo tecnomodificado, eles sugerem um "não" e solicitam, para si, a abertura para produzir formas de vida - e de pós-humanidade - paradigmáticas e ainda não inventadas.

\section{REFERÊNCIAS}

AGAMBEN, G. (2014). Homo sacer: o poder soberano e a vida nua I. Trad. Henrique Burigo. 2.ed. Belo Horizonte: Editora da UFMG.

AGAMBEN, G. (2010). Une biopolitique mineure - entretien avec Giorgio Agamben. Vacarme, n.10. Disponível em: http://www.vacarme.org/article255.html. Acesso em: 6 fev. 2014.

ARENDT, H. (2007).A condição bumana. Trad. Roberto Raposo. 10.ed. Rio de Janeiro: Forense Universitária.

BUTTURI JUNIOR, A.; LARA, C. A. (2018a). As narrativas de si e a produção da memória na campanha $\mathrm{O}$ cartaz HIV Positivo. Linguagem em (dis)curso (online), Tubarão, v. 18, p. 393-411. Disponível em: http://www.scielo.br/scielo.php?script=sci abstract\&pid $=$ S1518-76322018000200393\&lng $=$ pt\&nrm $=$ iso. Acesso em: 9 maio 2019.

BUTTURI JUNIOR, A.; LARA, C. A. (2018b). Biopolítica, direitos humanos e resistências: uma análise comparativa das políticas públicas de saúde para a população LGBT em Florianópolis-SC. Trabalhos em Linguística Aplicada, v. 27, p. 645-674. 
Disponível em: http://www.scielo.br/scielo.php?script=sci abstract\&pid=S0103$\underline{18132018000200645 \& \operatorname{lng}=\mathrm{pt \& nrm}=\text { iso. }}$. Acesso em: 9 maio 2019.

BUTTURI JUNIOR, A. (2016). As formas de subjetividade e o dispositivo da aids no Brasil contemporâneo: disciplinas, biopolítica e phármakon. In: QUINO, V. C.; CRESTANI, L. M.; DIAS, L. F.; DIEDRICHM M. S. Língua, literatura, cultura e identidade: entrelaçando conceitos. Passo Fundo: Editora da Universidade de Passo Fundo. p.59-78.

BUTTURI JUNIOR, A. (2012). A passividade e o fantasma: o discurso monossexual no Brasil. Tese (Doutorado) - Programa de Pós-Graduação em Linguística, Universidade Federal de Santa Catarina, Florianópolis,. Disponível em: https://repositorio.ufsc.br/ xmlui/bitstream/handle/123456789/96117/301572.pdf? sequence $=1$ \&isAllowed $=\mathrm{y}$. Acesso em: 9 maio 2019

BIEHL, J. (2004). The Activist State - Global pharmaceutical, AIDS, and citizenship in Brazil. Social Text 80, Durham, v. 22, nº 3, pp. 105-132.

BRASIL. Lei n. 9.313, de 13 de novembro de 1996. Dispõe sobre a distribuição gratuita de medicamentos aos portadores do HIV e doentes de AIDS. Diário Oficial da União, Poder Executivo, Brasília, DF. Disponível em: <http://www.planalto.gov.br/ ccivil_03/leis/L9313.htm>. Acesso em: 20 mar. 2016.

BRASIL. Sou + Estou Indetectável. 2018. Disponível em: http://www.aids.gov.br/ indetectavel/. Acesso em: 20 mar. 2019.

BUTLER, J. (2016). Quadros de guerra: quando a vida é passível de luto. 2.ed. Trad. Sérgio Lamarão e Arnaldo Marque da Cunha. Rio de Janeiro: Civilização Brasileira.

BUTLER, J. (2014). O clamor de Antígona: parentesco entre a vida e a morte. Florianópolis: Editora da UFSC.

CAMARGO JR., K. R. de. (1994). As ciências da AIDS e a AIDS das ciências: discursos médico e a construção da AIDS. Rio de Janeiro: Relume-Dumará, ABIA, IMS, UERJ.

CARRARA, S. (1994). A AIDS e a história das doenças venéreas no Brasil. In: PARKER, R. et al. (org.). A AIDS no Brasil. 2.ed. Rio de Janeiro: Relumé-Dumará: ABIA: IMS, UERJ.

DANIEL, H. (1989). Vida antes da morte. Rio de Janeiro: Jaboti. 
DANIEL, H. (1990). O primeiro AZT a gente nunca esquece. Jornal do Brasil, Rio de Janeiro, 30 set.

DANIEL, H.; PARKER, R. (1991). AIDS, a terceira epidemia: ensaios e tentativas. São Paulo: Iglu.

DE LAURETIS, T. (1994). Tecnologia do gênero. In: HOLLANDA, H. B. Tendências e Impasses: o feminismo como crítica da cultura. Rio de Janeiro: Rocco.

DELEUZE, G. (2013). Conversações. Trad. Peter Pál Pelbart, Rio de Janeiro: Ed.34.

DEPARTAMENTO DE VIGILÂNCIA, PREVENÇÃO E CONTROLE DAS IST, DOS HIV/AIDS E DAS HEPATITES VIRAIS. Nota informativa número 3 de 2018, que apresenta as recomendações de substituição (switch) de esquemas de terapia antirretroviral contendo ITRNN ou IP/r por Dolutegravir, para pessoas vivendo com HIV com supressão viral maiores de 12 anos de idade. 2018, Disponível em: http://www.aids. gov.br/pt-br/legislacao/nota-informativa-no-032018-covigcgvpdiahvsvsms. Acesso em: 10 jan. 2019.

DERRIDA, J. (2005). A farmácia de Platão. Tradução Rogério da Costa. 3.ed. São Paulo: Iluminuras.

DERRIDA, J. (2008). Gramatologia. Tradução Miriam Chnaiderman e Renato Janine Ribeiro. 2.ed. São Paulo: Perspectiva.

ESPOSITO, R. (2010). Bios: biopolítica e filosofia. Trad. M. Freitas da Costa. Lisboa: Edições 70.

FASSIN, D. (2006). Quand les corps se souviennent: expériences et politiques du sida en Afrique du Sud. Paris: La Découverte.

FOUCAULT, M. (2008). Nascimento da biopolítica: curso dado no Collège de France (19781979). Edição estabelecida por Michel Senellart, trad. Claudia Berliner. São Paulo: Martins Fontes.

FOUCAULT, M. (2009). História da sexualidade I: a vontade de saber. 19.ed. Trad. Maria Thereza Albuquerque e J. A. Guilhon Albuquerque. Rio de Janeiro: Edições Graal.

FOUCAULT, M. (2010a). Em defesa da sociedade - curso no Collège de France, 1975-1976. Trad. Maria Ermantina Galvão. 2.ed. São Paulo: Martins Fontes. 
FOUCAULT, M. (2010b ). Crise da medicina ou crise da antimedicina. Verve, n.18, p.167-194. Disponível em: $<$ https://revistas.pucsp.br/index.php/verve/article/ view/8646>. Acesso em: 10 abr. 2018.

GALVÃO, J. (2000). AIDS no Brasil: a agenda de construção de uma epidemia. Rio de Janeiro: ABIA; São Paulo: Ed. 34.

HARAWAY, D. (2009). Manifesto ciborgue: ciência, tecnologia e feminismo-socialista no final do século XX. In: HARAWAY, D.; KUNZRU, H.; TADEU, T. Antropologia do ciborgue: as vertigens do pós-humano. Trad. Tomaz Tadeu. Belo Horizonte: Autêntica Editora, p. 34-118.

HARDT, M.; NEGRI, A. (2001). Império. 3.ed. Rio de Janeiro; Record.

LATOUR, B. (1994). Jamais Fomos Modernos: ensaios sobre antropologia simétrica. Trad. Carlos Irineu da Costa: Rio de Janeiro: Edições 34.

LAZZARATO, M. (2006). As revoluções do capitalismo. Rio de Janeiro: Civilização Brasileira.

LECOURT, D. (2005). Humano Pós-bumano. A técnica e a vida. Tradução Luiz Paulo Rouanet. São Paulo: Edições Loyola.

MBEMBE, A. (2016). Necropolítica. Arte \& Ensaios. n. 32. Disponível em: < https://revistas. ufrj.br/index.php/ae/article/view/8993 > . Acesso em: 15 fev. 2019

MINISTÉRIO DA SAÚDE. Protocolo clínico e diretrizes terapêuticas para manejo da infecção por HIV em adultos. [31 jul. 2015].

MOULIN, A. M. (2011). O corpo diante da medicina. In: COURTINE, J. J. História do corpo: 3. As mutações do olhar: o século XX. 4. ed. Rio de Janeiro, Petrópolis: Vozes.

NEGRI, A. (2016). Quando e como eu li Foucault. Organização de Mario A. Marno. São Paulo: $\mathrm{n}-1$.

ORTEGA, F.; ZORZANELLI, R. (2010). Corpo em evidência: a ciência e a redefinição do humano. Rio de Janeiro: Civilização Brasileira.

PATTON, C. (1991). Inventing aids. Londres: Routledge.

PARKER, R. (2015). O fim da AIDS? .Associação Brasileira Interdisciplinar de Aids. 
PELÚCIO, L.; MISKOLCI, R. (2009). A prevenção do desvio: o dispositivo da aids e a repatologização das sexualidades dissidentes. Sexualidad, Salud y Sociedad - Revista Latinoamericana, p. 125-157.

PERLONGHER, N. (1987). O que é AIDS. 2.ed. São Paulo: Brasiliense.

POLLAK, M. (1990). Os bomossexuais e a AIDS: sociologia de uma epidemia. Trad. Paula Rosas. São Paulo: Estação Liberdade.

PRECIADO, P. B. (2008). Texto yonque. Madrid: Espasa.

RÜDIGER, F. (2007). Breve história do pós-humanismo: Elementos de genealogia e criticismo. Compós, p.1-17, abr.

SQUIRE, C. (2013). Living with HIV and ARVs: three-letter Lives. Londres: Palgrave Macmillan.

SLOTERDIJK, P. (2000). Regras para o parque bumano: uma resposta à carta de Heidegger sobre o humanismo. Tradução de José Oscar de Almeida Marques. São Paulo: Estação Liberdade.

SONTAG, S. (1989). A AIDS e suas metáforas. São Paulo: Companhia das Letras.

SOUTO, B. G. A. (2008). O HIV, seu portador e o tratamento anti-retroviral: implicações existenciais. São Carlos: EDUFSCAR.

TADEU, T. (2009) Nós, ciborgues. O corpo elétrico e a dissolução do humano. In: HARAWAY, D.; KUNZRU, H.; TADEU, T. Antropologia do ciborgue: as vertigens do pós-humano. Trad. Tomaz Tadeu. Belo Horizonte: Autêntica Editora.

TEODORESCU, L.; TEIXEIRA, P. (2015). Histórias da aids no Brasil. v. 1: as respostas governamentais à epidemia de aids. Brasília: Ministério da Saúde/Secretaria de Vigilância em Saúde/Departamento de DST, Aids e Hepatites Virais.

TREICHLER, P. A. (1987). AIDS, Homophobia, and biomedical discourse: an epidemic of signification. The MIT Press, v.47.

UNAIDS. 90-90-90. An ambitious treatment target to help end the AIDS epidemic, 2014. Disponível em: https://www.unaids.org/sites/default/files/media_asset/90-90-90 en.pdf. Acesso em 13 maio 2016. 
UNAIDS. Cerca de 21 milhões de pessoas vivendo com HIV estão em tratamento, diz novo relatório global do UNAIDS. 2017. Disponível em: https://unaids.org.br/2017/11/ cerca-de-21-milhoes-de-pessoas-vivendo-com-hiv-estao-em-tratamento-diz-novorelatorio-global-do-unaids. Acesso em: 10 jan. 2018.

VALDERRAMA, J. M. (2010). Medicalização da vida soropositiva. In: C APONI, S. et al (org.). Medicalização da vida: ética, saúde pública e indústria farmacêutica. Palhoça: Editora Unisul.

VERNAZZA, P. et al. (2008). Les personnes séropositives ne souffrant d'aucune autre MST et suivant un traitment antirétroviral efficace ne transmettent pas le VIH par voie sexuelle. Bulletin des Médecins Suisses, v.89, nº 5, pp.165-169.

Recebido: 1/06/2019

Aceito: 5/07/2019

Publicado: 13/08/2019 